\title{
Postmetamorphic ontogenetic allometry and the evolution of skull shape in Nest-building frogs Leptodactylus (Anura: Leptodactylidae)
}

\author{
Ana S. Duport-Bru (iD | María L. Ponssa | Florencia Vera Candioti
}

Unidad Ejecutora Lillo, (CONICET-Fundación Miguel Lillo), Tucumán, Argentina

\section{Correspondence}

Florencia Vera Candioti, Unidad Ejecutora Lillo (CONICET-Fundación Miguel Lillo), Miguel Lillo 251, 4000 Tucumán, Argentina. Email: florivc@gmail.com

\begin{abstract}
Allometry constitutes an important source of morphological variation. However, its influence in head development in anurans has been poorly explored. By using geometric morphometrics followed by statistical and comparative methods we analyzed patterns of allometric change during cranial postmetamorphic ontogeny in species of Nest-building frogs Leptodactylus (Leptodactylidae). We found that the anuran skull is not a static structure, and allometry plays an important role in defining its shape in this group. Similar to other groups with biphasic life-cycle, and following a general trend in vertebrates, ontogenetic changes mostly involve rearrangement in rostral, otoccipital, and suspensorium regions. Ontogenetic transformations are paralleled by shape changes associated with evolutionary change in size, such that the skulls of species of different intrageneric groups are scaled to each other, and small and large species show patterns of paedomorphic/peramorphic features, respectively. Allometric trajectories producing those phenotypes are highly evolvable though, with shape change direction and magnitude varying widely among clades, and irrespective of changes in absolute body size. These results reinforce the importance of large-scale comparisons of growth patterns to understand the plasticity, evolution, and polarity of morphological changes in different clades.
\end{abstract}

\section{K E Y W O R D S}

body size, evolutionary allometry, geometric morphometrics, paedomorphosis

\section{INTRODUCTION}

Ontogeny and evolution are intimately interrelated, and evolutionary changes in morphological characters require changes in the developmental processes that produce the structures of interest (Klingenberg, 1998). One of the dominant factors of morphological variation is allometry, which in a multivariate conception refers to the dependence of shape on size (Gould, 1966; Klingenberg, 2016). Allometry can be analyzed at several levels according to the source of size variation (Cock, 1966), that is, at an intraspecific level at a given developmental stage (static allometry), over development (ontogenetic allometry), and among species (evolutionary allometry). These levels can be studied separately or given their deep intertwining (Klingenberg, 1998, 2016), in combined approaches, such as the comparative study of interspecific (evolutionary) variations among developmental trajectories of closely related species (e.g., Ivanović, Vukov, Džukić, Tomašević, \& Kalezić, 2007). These approaches allow to interpret how allometric patterns at one level 
relate to patterns at another level (e.g., Klingenberg \& Zimmermann, 1992; Pélabon et al., 2013). In general, the evolution of ontogenies can occur either maintaining the shape/size relationship of the ancestral trajectory (i.e., ontogenetic scaling), or departing from it through changes in intercept or slope of that trajectory (i.e., lateral transpositions and rate changes, respectively; Strelin, Benitez-Vieyra, Fornoni, Klingenberg, \& Cocucci, 2016). The resulting diversification thus may include morphological patterns of paedomorphosis (i.e., the retention of ancestral juvenile characters in the descendant adult phase) and peramorphosis (i.e., the exaggeration of adult traits; Gould, 1977).

The frog skull represents a suitable and underexplored model to study the interplay between ontogenetic and evolutionary shape/size changes. As with exomorphological features, which are proven to be highly decoupled between larval and adult stages (Sherratt, Vidal-García, Anstis, \& Keogh, 2017), the skull undergoes a deep restructuring during development of biphasic-cycle species, associated to functional shifts in feeding, breathing, and sensorial system (Duellman \& Trueb, 1986; Emerson \& Bramble, 1993). In particular, morphological changes after anuran metamorphosis are decisive to the acquisition of the adult skull configuration. Despite the importance of this period, the role of allometry during cranial postmetamorphosis has been scarcely investigated (Birch, 1999; Ponssa \& Vera Candioti, 2012). On the other hand, macroevolutionary allometric patterns as related to cranial interspecific variation were studied in amphibians and other groups of tetrapods (Esquerré, Sherratt, \& Keogh, 2017; Ivanović \& Arntzen, 2014, 2018; Klingenberg \& Marugán-Lobón, 2013; Openshaw \& Keogh, 2014; Sherratt, Gower, Klingenberg, \& Wilkinson, 2014; Tavares, Pessôa, \& Seuánez, 2016; Wilson, 2013; Wilson \& Sánchez Villagra, 2011). Particularly in anurans, several authors have addressed large-scale studies about skull morphological diversification (e.g., Emerson, 1985; Simon \& Marroig, 2017; Simon, Machado, \& Marroig, 2016; Yeh, 2002a), but to our knowledge, patterns of postmetamorphic skull development and their relationship with diversity in adult morphology have been explored in a few clades (Fabrezi, 2006; Fabrezi et al., 2016; Ponssa \& Vera Candioti, 2012; Yeh, 2002b).

In this study, we analyze ontogenetic and evolutionary shape/size relationships in the skull of the Nest-building frogs Leptodactylus (Anura: Leptodactylidae). This genus currently includes 74 species that exhibit a wide range of body sizes, about a fourfold difference between the largest (e.g., $154 \mathrm{~mm}$ of mean snout-vent length in Leptodactylus vastus of the Leptodactylus pentadactylus intrageneric group) and the smallest species (e.g., $35 \mathrm{~mm}$ in Leptodactylus latinasus of the Leptodactylus fuscus gr.; de Sá et al., 2014). The clade then offers an interesting case to study shape/size change patterns, since it has been suggested that in groups in which variation in body size is pronounced, the relationship between morphological parameters and body size can provide valuable information about the developmental base of morphological variation among species (Shea, 1985). By applying geometric morphometrics followed by a variety of statistical and comparative methods, we propose: (a) to discern the effect of size changes on the morphological diversity of Leptodactylus adult skulls (evolutionary allometry); (b) to describe shape changes in the skull related to size increase during postmetamorphic development of each species (ontogenetic allometry); (c) to investigate interspecific variations in skull allometric ontogenetic patterns and their relationships with morphological diversity in adult skulls (evolution of ontogenetic allometry); and (d) to integrate and discuss patterns of cranial development in the context of body size evolution within the genus (cranial allometry and size evolution). As suggested in other tetrapod groups (e.g., revised in Tavares et al., 2016), we expect to find a common allometric developmental trajectory for different-sized species, and adult morphological diversification explained mainly by ontogenetic scaling, with small species showing paedomorphic morphology due to size reduction, and large species showing peramorphic shapes product of size increase.

\section{2 | MATERIALS AND METHODS}

\subsection{Specimens and shape description}

We studied 34 species of Leptodactylus, representing the four intrageneric groups and about a half of the recognized species of the genus. To interpret allometric patterns in an evolutionary context of Leptodactylinae, we also include four species of Adenomera, the sister group of Leptodactylus that gathers the smallest species in the subfamily (Table S1). Adenomera species were formerly considered members of the Leptodactylus marmoratus group, before being erected as a monophyletic genus by de Sá et al. (2014); they show several features interpreted as paedomorphic (Ponssa \& Heyer, 2007), and thus represent an interesting clade to compare allometric developmental patterns with Leptodactylus. Following recent evidence that revealed the nonmonophyly of $L$. fuscus and L. mystaceus (de Sá et al., 2014), we include representatives of the basal lineage of $L$. mystaceus, and of two different lineages of $L$. fuscus (further details in Table S1). A total of 386 metamorphic and adult specimens were processed for analyses of the postmetamorphic cranial anatomy (Table S1). Assessment of sexual maturity and identification of adult males were based on the presence of secondary sexual characters (e.g., colored vocal sacs and nuptial excrescences); sexual maturity of females was based 
on examination of the gonads. Most specimens were cleared and double-stained for bone and cartilage following Wassersug, (1976) technique, and dry skeletal preparations were also examined. The terminology for cranial osteology follows that of Trueb, Púgener, and Maglia (2000).

We applied standard geometric morphometrics to describe and compare ontogenetic and evolutionary shape variations in cranial morphology. Sexual dimorphism is common in anurans (e.g., Vukov, Krstičić, Petrović, \& Tomašević Kolarov, 2018), and a differential sampling of sexes would be expected to inflate the variance and influence the orientation of allometric trajectories. So, we started by exploring the presence of sexual dimorphism on skull shape and size in adults of two Leptodactylus species with a representative sample of both sexes, Leptodactylus bufonius and Leptodactylus melanonotus. On this partial data set we also quantified other sources of variation, hypothesizing that interspecific variation would exceed eventual intraspecific variation related to sexes and cranial symmetry. Skulls in dorsal and ventral views were photographed with a 591CU digital camera mounted on a Nikon SMZ18 stereomicroscope, and three photographs per specimen were used. The same person (ASDB) digitized 40 dorsal and 54 ventral bilateral landmarks, using TpsDig 2.17 (Rohlf, 2013; Table S2). Landmark selection was based on Vera and Ponssa (2014), redefining some points when necessary. Criteria for selection include their ease of identification in all specimens and their utility to represent the entire geometric form and to provide functional descriptions of important regions of the skull. Landmark configurations were then submitted to MorphoJ software (Klingenberg, 2011), where Generalized Procrustes Analysis (GPA) was performed to obtain a shape coordinate matrix to be used in subsequent analyses. The skull size of each specimen was calculated as centroid size, and the log-transformed centroid size $(\log C S)$ was used because it yields a more linear relationship between size and shapes for ontogenetic allometry (Strelin, Benitez-Vieyra, Fornoni, Klingenberg, $\&$ Cocucci, 2018). The relative contributions of the various sources of shape variation (sexual dimorphism, symmetry, and measurement error) were assessed by a Procrustes analysis of variance, an extension of the two-factor ANOVA for morphogeometric data, which quantifies the amount of shape variation for different effects using Procrustes distance (Klingenberg, Debat, \& Roff, 2010). Given that interspecific variation exceeded to a large extent the other sources of variation (see summarized results in the next section and in Table S3), and to deal with the loss of landmarks due to damaged or incomplete skulls, the full data set was analyzed considering sexes together and only half of the landmark configuration. A total of 21 dorsal and
27 ventral landmarks on the right half of each image was digitized (Figure 1), and we followed the protocol described above to obtain the Procrustes coordinates and centroid sizes.

We analyzed the relationship between shape change and size change in postmetamorphic cranial configurations, by exploring the two main sources of size variation in our data set: evolution and ontogeny. In the context of geometric morphometrics, where the shape is considered as a multivariate concept separated from size, allometry is defined as the statistical association between shape and size (Klingenberg, 2016). The test for allometry consists of a multivariate regression of shape coordinates on logtransformed centroid size, and the statistical significance of the regression is assessed with a permutation test. The null hypothesis being tested states that shape develops isometrically; thus, a significant relationship points out that shape changes according to a predictable model with increasing size, whereas a nonsignificant relationship indicates isometry (Esquerré et al., 2017). The amount of variation for which the regression model accounts is quantified as a percentage of the total shape variation, computed using Procrustes metric (Klingenberg, 2016). The vector of regression coefficients of the multivariate regression (i.e., the vector of bivariate regression coefficients of the shape variables on $\log C S$ ) is then used to compute regression scores by projecting the data points onto an axis in the direction of the regression vector; this shape variable is an optimal summary variable and can be plotted against $\log C S$ to show how shape changes in response to size increase (Drake \& Klingenberg, 2008; Mitteroecker, Gunz, Windhager, \& Schaefer, 2013).

\section{2 | Evolutionary allometry}

To test if the evolutionary change of skull shape is associated with the evolutionary change of skull size, we worked on a data set including averages of cranial Procrustes coordinates and centroid sizes of adult specimens of all 38 species considered. We tested the phylogenetic signal in the data set by using a permutation approach that simulates the null hypothesis of no phylogenetic signal by randomly exchanging the shape data among the tips of the phylogenetic tree (Klingenberg $\&$ Gidaszewski, 2010). With a significant $p$-value, the phylogenetic structure in the data set needs to be taken into account, and a matrix of phylogenetically independent contrasts (Felsenstein, 1985) is used instead for further analyses. We then performed a multivariate regression of independent contrasts of shape (Procrustes coordinates) on independent contrasts of size (log centroid size). To interpret patterns of shape/size variation in terms of species, we projected the original 

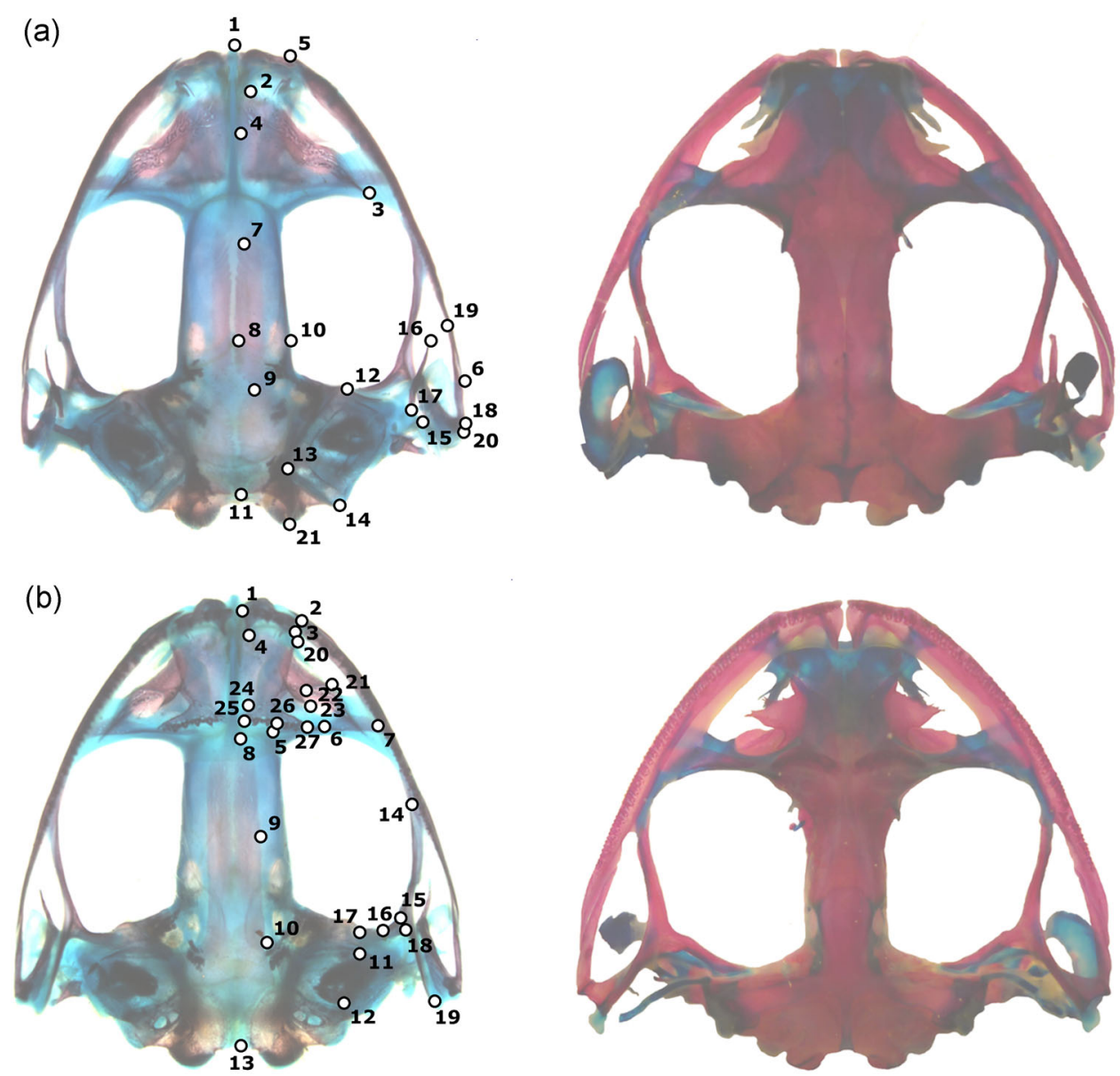

F I G U R E 1 Landmarks digitized on dorsal (a) and ventral (b) skulls of metamorphic (MZUSP 21389; left) and adult (UFRJ 34313; right) specimens of Leptodactylus syphax, as defined in Table S2 [Color figure can be viewed at wileyonlinelibrary.com]

Procrustes coordinates data set into the regression of independent contrasts (Klingenberg \& Marugán-Lobón, 2013). All calculations for this section were done using MorphoJ software (Klingenberg, 2011).

\section{3 | Ontogenetic allometry and evolution of ontogenetic trajectories}

To explore how the evolutionary pattern in adult skull allometry is related to cranial development, we studied patterns of ontogenetic allometry per species and compared them interspecifically. We worked on a data set composed of metamorphic and adult specimens of 13 species, and first we analyzed size-related shape changes during skull development (ontogenetic allometry) by performing regressions of shape on size separately for each of them (Ponssa \& Vera Candioti, 2012). We include only those species with $N \geq 7$ and well-represented trajectories (in terms of size ranges), and we tried to moderate the small sample size by performing nonparametric, permutation tests for statistical analyses. Calculations were done using MorphoJ software (Klingenberg, 2011).
We then explored how allometric trajectories vary in shape and shape/size spaces, by using a combination of visual and quantitative approaches. We followed Adams and Nistri (2010) and Esquerré et al. (2017) to perform a principal component analysis (PCA) on Procrustes coordinates, and a pooled-within species multivariate regression of shape on size of metamorphs and adults of the 13 species. To summarize patterns of variation in shape and allometric trajectories and facilitate species-level comparisons, we overlapped the averages per developmental stage to the original distributions of shape coordinates in PCA plots, and in addition to the regression scores, we show the first principal component of the matrix of predicted shape values plotted against log-centroid size. Next, to quantify interspecific variations in allometric patterns, we followed the approximation by Collyer and Adams (2013), which consists of a test of homogeneity of slopes using a distance-based analysis of covariance (ANCOVA) on skull shape including size, species, and the interaction between the two terms. The test calculates the amount of shape variation explained by size, the allometric slopes for each species, and performs pairwise comparisons for the slope angles (direction of shape 
change with size) and slope lengths (magnitude of shape change per unit of size change). This test was performed using the advanced.procD.lm function in the $\mathrm{R}$ package geomorph v.3.0.6 (Adams, Collyer, \& Kaliontzopoulou, 2018), assessing statistical significance with a residual randomization permutation procedure with 10,000 iterations.

\subsection{Cranial allometry and body size evolution}

Finally, we studied the evolution of patterns of cranial allometry in Leptodactylus phylogeny and the association between changes in skull allometry and changes in adult body size throughout the tree. The most comprehensive phylogenetic hypothesis for the genus is that of de Sá et al. (2014), and we used a modified version of it, by including only the species under study and Adenomera hylaedactyla and Adenomera marmorata as the outgroup. We applied delayed-response phylogenetic correlation (DELCOR; Giannini \& Goloboff, 2010), a way of correlation/regression that connects inner-node reconstructions of two characters, under the null hypothesis that they have uncorrelated changes. We set body size (measured as snout-vent length; data are taken from AmphibiaWeb, 2017 and de Sá et al., 2014) as the independent variable. As the dependent variable representing the skull ontogenetic trajectory, we used the length of the allometric slope (as calculated in the previous test). The analysis first reconstructs ancestral states for body sizes and slope lengths as continuous characters by using estimated confidence intervals for each of them. Then it tests whether changes in the length of allometric trajectories responded to changes in body size (tree-up testing). Unlike a standard analysis where the correlation of variables at the same terminal/node would be tested, DELCOR allows the response change in the dependent character to be delayed with respect to change in the other character, then testing pairs that do not necessarily match at the same node. We used a randomized maximum radius of three nodes with five cycles, with all branches set to unity, and sampling 100 combinations of reconstructions to calculate a range of observed $r$ values. If the range of observed $r$ values includes zero, the test indicates no correlation between variables; if the range does not include zero, randomization estimates a significance $p$ value for the correlation. Analyses were performed with TNT version 1.5 (Goloboff \& Catalano, 2016; delcor.run).

\section{3 | RESULTS}

\section{1 | Intraspecific variations}

Procrustes analysis of variance (ANOVA) on the cranial shape of $L$. bufonius and L. melanonotus yielded highly significant effects of all sources of intraspecific variation (Table S3). Both for dorsal and ventral views, total intraspecific variation contributes to a lesser extent to skull shape than interspecific variation; the relative magnitudes of the mean squares show that the effect of sexual dimorphism masks directional and fluctuating asymmetry, and in turn symmetry variations exceed measurement error.

\section{2 | Evolutionary allometry}

The permutation test found a statistically significant phylogenetic signal $(p<.0001)$ both for dorsal and ventral skull shapes. Multivariate regression of independent contrasts of shape and size in 34 Leptodactylus and four Adenomera species resulted significant both in dorsal and ventral configurations of the skull and in ventral view allometry accounts for three times the percentage of variation than in dorsal view $(p<.05 ; 17.58 \%$ and $5.79 \%$, respectively). The scatterplot of species corrected by phylogeny (Figure 2) shows that the species groups of Leptodactylus arrange along the regression vector from small to large species, that is, with $L$. fuscus-L. melanonotus and L. pentadactylus groups on the extremes. Small adults of the L. fuscus gr. (e.g., L. latinasus and Leptodactylus camaquara) occupy the lowest edge of the shape/size distribution, whereas large adults of the group (e.g., Leptodactylus syphax and Leptodactylus laticeps) overlap with size range of species of the Leptodactylus latrans gr. and with shape values also closer to species of the L. pentadactylus gr. In turn, in dorsal configuration Adenomera species combine the smallest skulls with shapes that distribute within the variation range of species of L. fuscus and L. melanonotus groups, whereas on ventral configurations they occupy their own sector in shape/size space. Shape changes associated with size show that smaller skulls are overall narrow, with smaller nasals, larger and quadrangular otic capsules, short and curved neopalatines, dentigerous processes straight and arranged oblique to the longitudinal axis of the skull, and pterygoids not surpassing the parasphenoids caudally.

\section{3 | Ontogenetic allometry and evolution of ontogenetic trajectories}

Skull shape change both in dorsal and ventral views was significantly related to skull size change in all Leptodactylus species $(p<.02$; Table 1$)$. The single species where the hypothesis of isometry was not rejected was A. marmorata, but this could be due also to incomplete sampling of its developmental trajectory. Percentages of variation explained by size are very large (about 30-70\%), excepting L. latinasus that shows the lowest values (about 15\%). Figure 3 shows the shape (Figure 3a) and shape/size trajectories (Figure 3b) of 
(a)

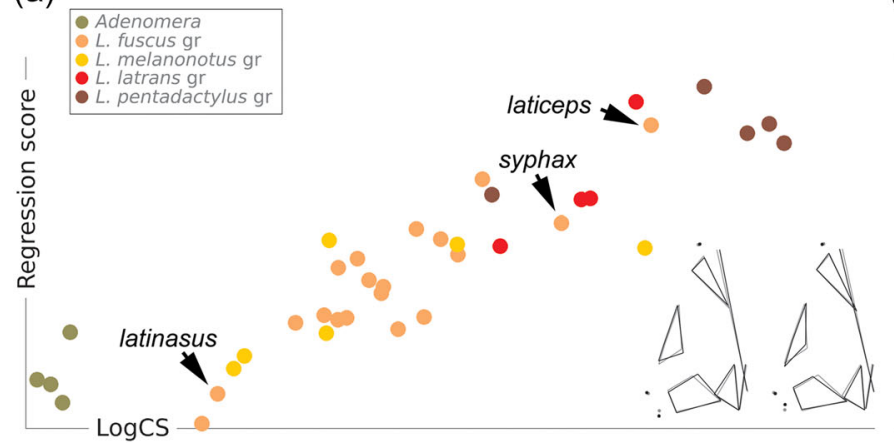

(b)

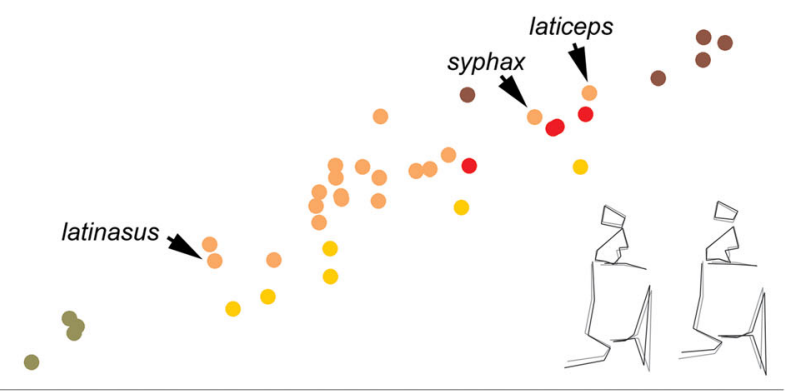

FIG URE 2 Evolutionary allometry in dorsal (a) and ventral (b) skulls of adult specimens of the four intrageneric groups of Leptodactylus and Adenomera, based on multivariate regression of shape (summarized as regression scores) on size (logCS). Wireframe graphs depict skull shape in small (left) and large-sized (right) species regarding an average configuration (grey lines). Note shape/size relationship in small and large species of the Leptodactylus fuscus gr. (Leptodactylus latinasus vs. Leptodactylus laticeps and Leptodactylus syphax, respectively) as compared with species of other clades [Color figure can be viewed at wileyonlinelibrary.com]

13 species, in dorsal (top) and ventral (bottom) skull configurations. The scatterplots of the first two principal components (together accounting for about $40 \%$ of the shape variation in both views) show that $\mathrm{PCl}$ summarizes ontogenetic shape change whereas $\mathrm{PC} 2$ allows to detect some interspecific variation. PC1s ordinations show that adult specimens have wider posterior skulls, enlarged nasals, larger vomers with wide and curved dentigerous processes, straighter neopalatines, and shorter posterior regions of the parasphenoids. Shape change along PC2s mainly involves variations in proportional size of frontoparietals, squamosals, vomers, and pterygoids, and patterns of interspecific variations vary between dorsal and ventral skull views. Dorsally, species of the L. fuscus gr. have smaller bones; ventrally, adults of small L. latinasus mostly resemble metamorphs of all species, whereas adults of large $L$. syphax tend to overlap in morphospace with adults of the $L$. pentadactylus gr. In turn, scatterplots of predicted skull shapes on size show that species of the L. pentadactylus gr. have larger and peramorphic adult skulls as compared with species of the

TABLE 1 Tests statistics and sample size from the test for allometry for each species, under the null hypothesis of isometry

\begin{tabular}{|c|c|c|c|c|c|}
\hline & \multirow[b]{2}{*}{$\boldsymbol{N}$} & \multicolumn{2}{|l|}{ Dorsal } & \multicolumn{2}{|l|}{ Ventral } \\
\hline & & $\%$ predicted & $p$ & $\%$ predicted & $p$ \\
\hline \multicolumn{6}{|l|}{ Leptodactylus pentadactylus gr. } \\
\hline Leptodactylus labyrinthicus & 17 & 33.84 & .0001 & 51.28 & $<.0001$ \\
\hline Leptodactylus podicipinus & 13 & 40.94 & $<.0001$ & 37.70 & $<.0001$ \\
\hline Leptodactylus wagneri & 15 & 31.17 & .0005 & 35.56 & .0002 \\
\hline \multicolumn{6}{|l|}{ Leptodactylus latrans gr. } \\
\hline Leptodactylus chaquensis & 20 & 23.68 & $<.0001$ & 35.72 & $<.0001$ \\
\hline Leptodactylus bufonius & 29 & 28.49 & $<.0001$ & 40.61 & $<.0001$ \\
\hline Leptodactylus latinasus & 46 & 16.26 & $<.0001$ & 15.04 & $<.0001$ \\
\hline Leptodactylus mystaceus & 11 & 39.91 & .0012 & 63.41 & $<.0001$ \\
\hline Leptodactylus fuscus & 9 & 55.41 & .006 & 54.92 & .0048 \\
\hline Leptodactylus elenae & 24 & 32.60 & $<.0001$ & 27.22 & $<.0001$ \\
\hline
\end{tabular}

Note: Specimens of Leptodactylus fuscus included in this analysis correspond to the lineage Leptodactylus fuscus 6-9 of de Sá et al. (2014). 
(a)
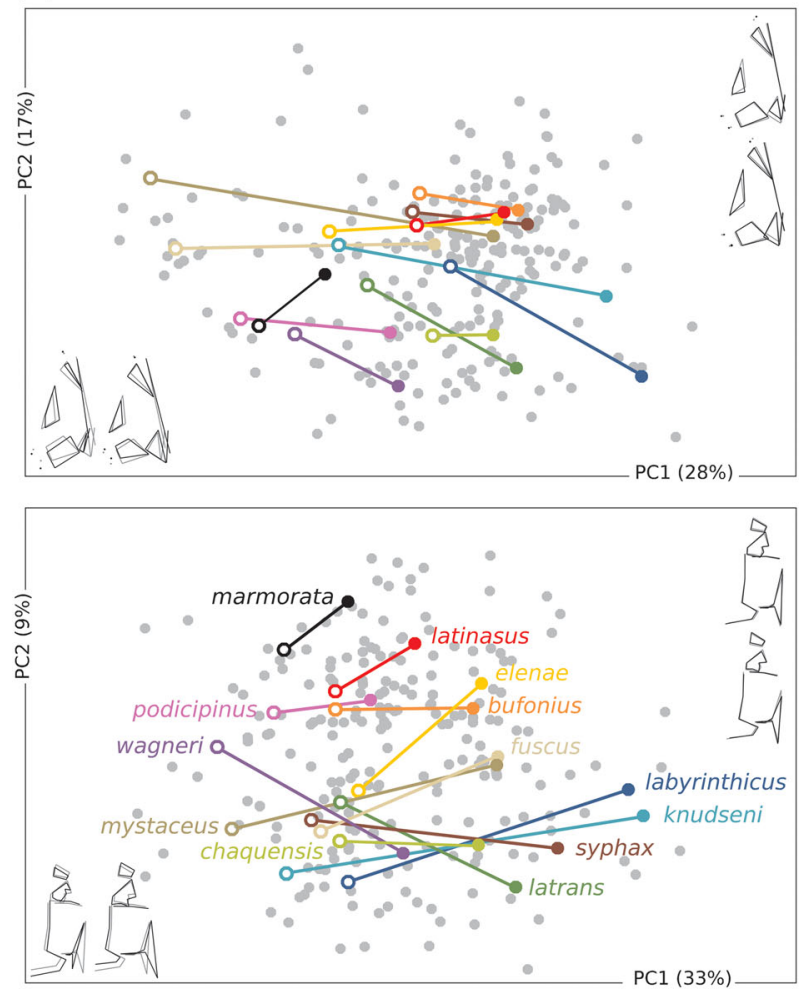

(b)
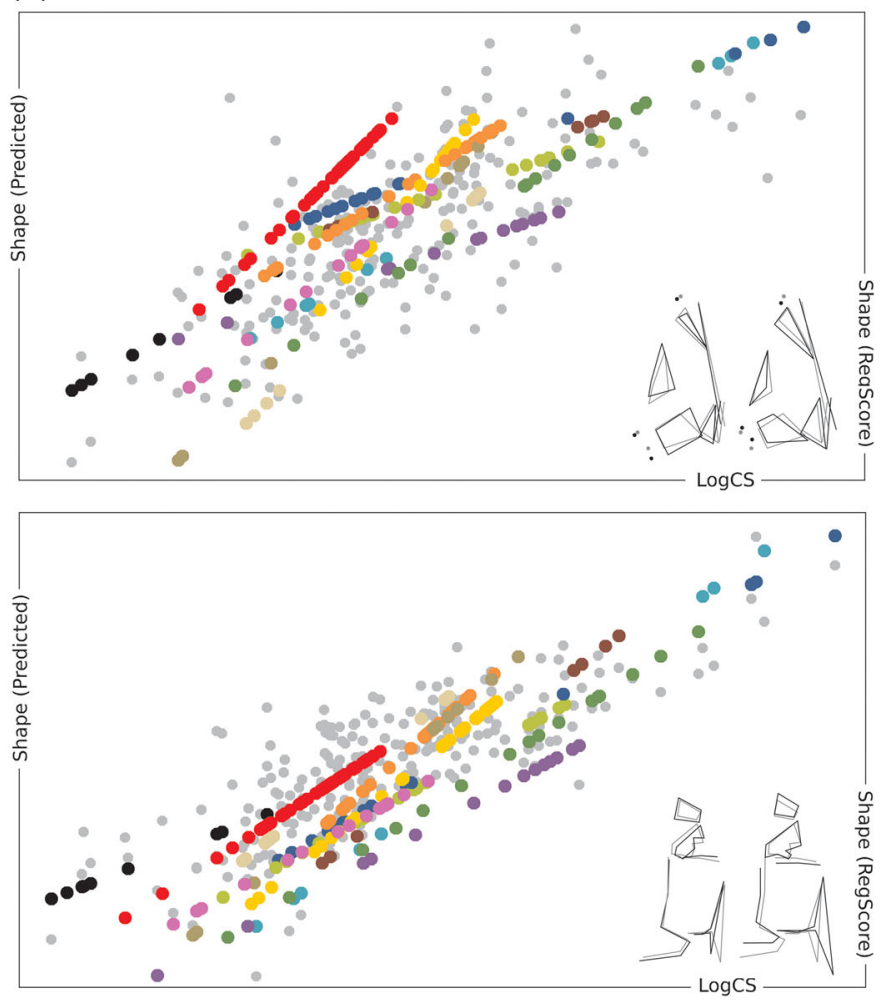

F I G URE 3 Shape and shape/size variations on metamorphic and adult specimens of Leptodactylus and Adenomera species, in dorsal (top) and ventral (bottom) skull views. Specimens of Leptodactylus fuscus included in this analysis correspond to the lineage L. fuscus 6-9 of de Sá et al. (2014). (a) Principal component plots show the raw distribution (grey) and average configurations per stage/species (metamorphs-colored empty symbols, adults-colored solid symbols). Wireframes show shape changes along principal components, regarding a consensus configuration (grey lines). (b) Regression plots depict the raw distribution of regression scores (grey) and PC1 of predicted shapes (colored) against size. Wireframes show shape changes in small and large specimens, regarding a consensus configuration (grey lines). Note the large and peramorphic skulls of Leptodactylus labyrinthicus and Leptodactylus knudseni (Leptodactylus pentadactylus gr.), in contrast to small, paedomorphic skulls of Leptodactylus latinasus (L. fuscus gr.) and Adenomera marmorata [Color figure can be viewed at wileyonlinelibrary.com]

other groups; allometric trajectories also start from already advanced onsets. On the other extreme, Adenomera and L. latinasus have small, paedomorphic skulls resembling the size/shape of metamorphs of L. syphax, L. latrans, and L. pentadactylus groups.

Pairwise comparisons in angles and lengths of allometric slopes are shown in Table 2. In about $70 \%$ of cases, species differ in at least one parameter and differences, in general, involve species from different intrageneric groups. Leptodactylus labyrinthicus differs from almost all other species, in both cranial configurations. Within the L. fuscus group, species are in general more different to each other in skull dorsal view, and more divergent species are $L$. latinasus (in ventral configuration) and Leptodactylus elenae and L. syphax (in dorsal configuration). Regarding the type of change, most intergroup differences are in slope direction, excepting the L. fuscus gr. that, in general, differs from the remaining in slope lengths. In dorsal configuration differences in slope lengths are almost twice more frequent than in slope directions, and explain almost all differences within the L. fuscus gr. In turn, ventral allometric trajectories mostly differ in slope angles. In general, L. elenae shows different lengths, and $L$. latinasus differences involve slope lengths in intragroup comparisons but slope angles regarding species of other groups.

\section{4 | Cranial allometry and body size evolution}

Figure 4 depicts the state distribution and ancestral reconstructions of body size and cranial allometric slope lengths for Leptodactylus and Adenomera species (a complete graph showing optimized values is shown in Figure S1). The optimization of adult body size across the whole tree shows an initial wide difference between ancestral body sizes of the two genera. Body size enlarges in the clade of $L$. latrans gr. that excludes Leptodactylus silvanimbus, at the base and progressively within the 
TABLE 2 Pairwise comparisons in slope angle and slope length (between parentheses) of cranial allometric trajectories

\begin{tabular}{|c|c|c|c|c|c|c|c|c|c|c|c|c|c|}
\hline & mar & $l a b$ & knu & pod & wag & $\operatorname{cha}$ & lat & syp & buf & lan & mys & fus & ele \\
\hline labyrinthicus & $*$ & & * & $(*)$ & $* *$ & $* *$ & $(*)$ & & $*(* *)$ & $*(* *)$ & $(* *)$ & $(* *)$ & $(* *)$ \\
\hline podicipinus & & $*$ & & & $*$ & $*(*)$ & & $(*)$ & & & & & $(* *)$ \\
\hline wagneri & $* *$ & $* *$ & $* *$ & & & $* *$ & $* *$ & $*$ & $* *(*)$ & $(* *)$ & $* *(* *)$ & $* *(* *)$ & $*(* *)$ \\
\hline latrans & $* *$ & $* *$ & & & & & & & & $(*)$ & $(*)$ & & $(* *)$ \\
\hline syphax & $* *$ & $* *$ & & & $*(*)$ & $(*)$ & & & $*(*)$ & $(* *)$ & $(* *)$ & $(* *)$ & $(* *)$ \\
\hline bufonius & $* *$ & $* *(* *)$ & & $*$ & $* *(* *)$ & $*(* *)$ & $(*)$ & & & & & & $(*)$ \\
\hline latinasus & $* *$ & $* *$ & & & $*$ & & * & & & & & & $(*)$ \\
\hline
\end{tabular}

Note: Original parameters and $p$-values are included in Table $\mathrm{S} 4$ and here replaced by significance levels $\left({ }^{*} 0.05\right.$ and $\left.{ }^{* *} 0.01\right)$. Dorsal (above diagonal) and ventral (below diagonal) skull comparisons are shown, and boxes highlight those comparisons within intrageneric groups. Specimens of Leptodactylus fuscus included in this analysis correspond to the lineage Leptodactylus fuscus 6-9 of de Sá et al. (2014).

L. pentadactylus gr., and within the L. fuscus gr. in the clade joining L. laticeps and L. syphax. Conversely, size is reduced in the clade of the $L$. fuscus gr. that joins $L$. fuscus $+L$. camaquara, in a more derived clade that includes L. latinasus, and at the base and progressively within the L. melanonotus gr. Delayed-response correlation analysis results show that changes on the length of skull allometric slopes are not significantly associated to changes in the body size (the range of observed $r$ values in ventral skull includes zero, and dorsal skull randomizations yield $p>.3$ ). Instead, similar slope length changes may follow both body size increases and reductions. Skull shape changes become stronger at the base and progressively within the $L$. fuscus gr., and only in Leptodactylus knudseni of the $L$. pentadactylus gr. Conversely, a less pronounced skull shape change occurs in large (L. syphax and L. labyrinthicus), mid-sized (Leptodactylus chaquensis and Leptodactylus wagneri), and small species (L. latinasus).

\section{4 | DISCUSSION}

Allometric patterns and how they influence head development have been explored in several tetrapod clades, including urodelans (Ivanović \& Arntzen, 2014, 2018; Ivanović, Cvijanović, \& Kalezić, 2011; Ivanović et al., 2007), caecilians (Sherratt et al., 2014), squamates (Esquerré et al., 2017; Hipsley \& Müller, 2017; Openshaw \& Keogh, 2014; Urošević, Ljubisavljević, \& Ivanović, 2013), turtles (Wilson \& Sánchez Villagra, 2011), birds (Klingenberg \& Marugán-Lobón, 2013), and diverse mammalian groups (e.g., Cardini, Polly, Dawson, \& Milne, 2015; Flores, Giannini, \& Abdala, 2018; Giannini, 2014; Gonzalez, Perez \& Bernal, 2011; Segura, Cassini, \& Prevosti, 2016). In this context, our results provide some hints to interpret the relationships among body size evolution, adult skull shape, and skull ontogeny in species of the anuran genus Leptodactylus.

General patterns of skull ontogenetic allometry in leptodactyline frogs are similar to those found in other groups with biphasic life-cycles (e.g., shortening and widening of the otoccipital region, and changes in size and arrangement of vomerine and suspensorium regions (Cvijanović, Ivanović, Kalezić, \& Zelditch, 2014; Ivanović et al., 2007). Some of these morphological changes have been related to functional changes that occur throughout the postmetamorphic ontogeny, mainly in feeding performance (Birch, 1999; Cvijanović et al., 2014; Emerson \& Bramble, 1993), and follow a general, modular developmental pattern in vertebrates, where the neurocranium becomes smaller and the face and snout proportionally larger with growth (Hanken \& Hall, 1993).

Ontogenetic, static and evolutionary allometry can be strongly correlated (e.g., revised in Pélabon et al., 2013). For instance, large-scale studies show that part of the ontogenetic transformations may be paralleled by shape changes associated with evolutionary change in size, suggesting that developmental modularity intervenes significantly in skull shape evolution (e.g., Ivanović \& Arntzen, 2014, 2018). Although always accompanied by non-allometric changes related to diverse functional, ecological, or even unknown aspects, it is usually possible 


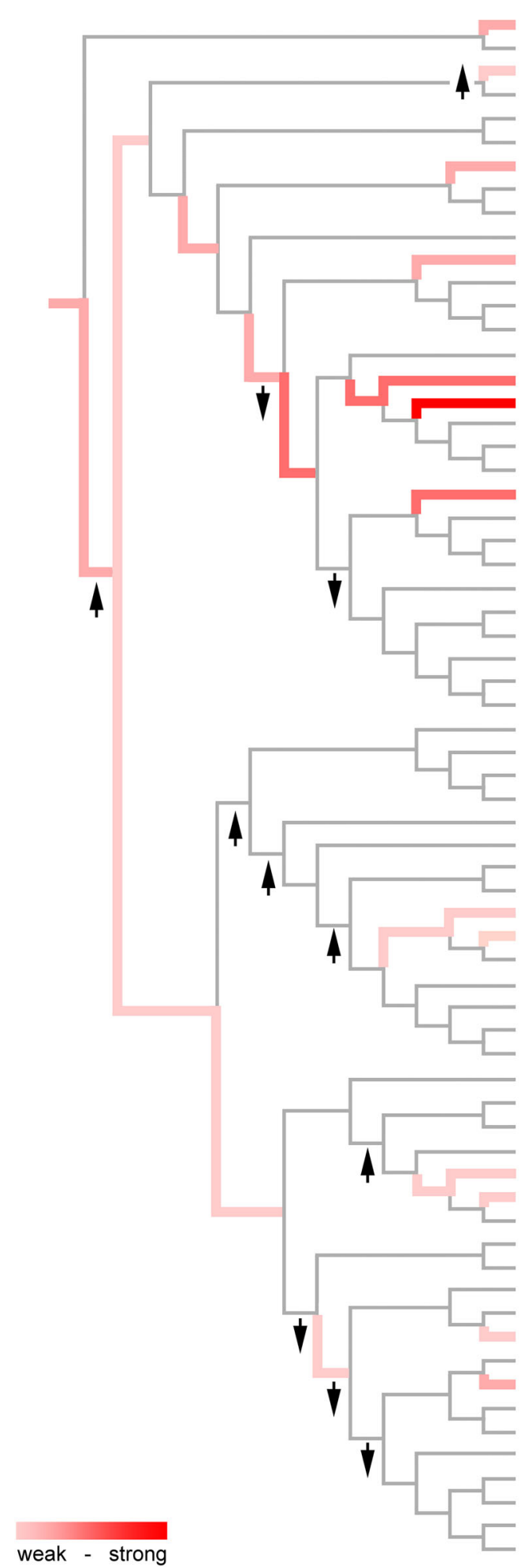

A. marmorata
A. hylaedactyla
L. syphax
L. laticeps
L. labrosus

L. ventrimaculatus

L. bufonius

L. mystacinus

L. troglodytes

L. albilabris

L. fuscus

L. fragilis

L. longirostris

L. poecilochilus

L. didymus

L. mystaceus

L. elenae

L. notoaktites

L. fuscus

L. mystaceus

L. latinasus

L. gracilis

L. jolyi

L. sertanejo

L. tapiti

L. marambaie

L. plaumanni

L. cunicularius

L. camaquara

L. furnarius

L. litonaethes

L. rugosus

L. rhodomystax

L. rhodonotus

L. flavopictus

L. stenodema

L. paraensis

L. vastus

L. knudseni

L. labyrinthicus

L. fallax

L. myersi

L. peritoaktites

L. pentadactylus

L. savagei

L. silvanimbus

L. bolivianus

L. insularum

L. viridis

L. latrans

L. chaquensis

L. macrosternum

L. melanonotus

L. riveroi

L. vallidus

L. colombiensis

L. wagneri

L. diedrus

L. podicipinus

L. discodactylus

L. griseigularis

L. nesiotus

L. leptodactyloides

L. petersii

L. natalensis

L. pustulatus
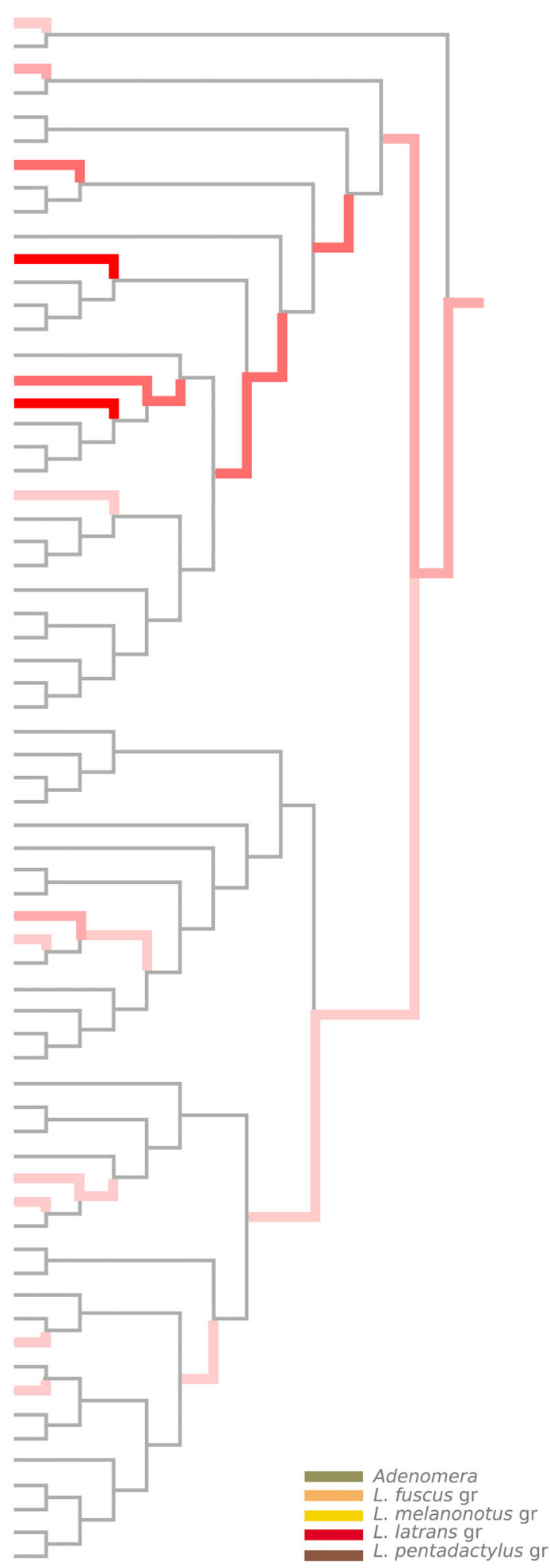

F I G URE 4 Adult body size and amount of skull shape change evolution in dorsal (left) and ventral (right) cranial configurations of Nest-building frogs, as inferred on the phylogenetic hypothesis by de Sá et al. (2014). Species in grey were not included in our work (their size data are taken from literature), and species in red are those submitted to ontogenetic allometry analysis. Color scale shows the magnitude of skull shape change during ontogeny (from weak to strong change, light to darker colors), and arrows indicate those nodes where body size increases (pointing-up arrows) or reduces (pointing-down arrows). Note the lack of correlation between body size changes and skull allometric patterns [Color figure can be viewed at wileyonlinelibrary.com] 
to trace paedomorphic/peramorphic cranial phenotypes that result from size reduction or size increase within several clades. How the general evolutionary patterns correlate with the diversity of ontogenetic allometric trajectories may vary among clades and with taxonomic levels (Weston, 2003). In some squamates, closely related species tend to show common allometric growth patterns, whereas shifts in direction of ontogenetic allometry are more frequent among distant clades (Esquerré et al., 2017; Piras et al., 2011). Other studies highlight a widespread evolvability in allometric patterns (e.g., chelid turtles and salamanders; Cvijanović et al., 2014; Ivanović \& Arntzen, 2018; Ivanović et al., 2007; Wilson \& Sánchez Villagra, 2011), or alternatively, highly conserved growth patterns that link intraspecific ontogenetic with macroevolutionary allometry (marsupial and placental mammals; Cardini et al., 2015). In this last sense, Hipsley and Müller (2017) argue that transformations to the shape/ size covariance during lacertid postnatal ontogeny can break down functional relationships between traits and are thus selected against. In Leptodactylinae frogs, adult skulls of small to large species are clearly scaled over a common evolutionary allometric model. However, skull ontogenetic trajectories are highly variable, especially among intrageneric groups, and do not correlate with shifts in adult body size along with the clade. This shows that, unlike expected, the evolution of skull shape within this group does not necessarily result from maintaining an ancestral relationship between size and shape, but diverging ontogenetic trajectories where this relationship is transformed may also render adult skulls scaled to each other. This is consistent with an initial wide disparity in shape and size of metamorphs (Ponssa \& Vera Candioti, 2012), while a scenario where ontogenetic scaling predominates over other allometric changes would be possible only starting from more similar shape/size onsets.

Derived species within the $L$. fuscus gr. (e.g., L. latinasus and $L$. camaquara) are the smallest species in the genus. Some morphological features in their adult skulls, mainly in ventral bones (e.g., small vomers, straight dentigerous processes, straight margins in the cultriform processes), resemble traits of metamorphs of other species, and were already discussed as paedomorphic (Ponssa, 2008). Based on the adult size of L. latinasus as compared with basal species of the group, Ponssa and Vera Candioti (2012) pointed out that size decrease in this species could be considered as a case of miniaturization within the $L$. fuscus group, in this case not associated with loss of bones like in other groups (Trueb \& Alberch, 1985), but to paedomorphic shape of the whole skull and some individual bones. The conservation of the shape/size trajectory of basal forms, combined with an overall weaker skull shape change, indicates that in this species small size and paedomorphic skull shape result from ontogenetic scaling. Small species of Adenomera share morphological and developmental features with species of the L. fuscus gr. (Ponssa \& Heyer, 2007), and also several convergent characters related to the capacity to build incubation chambers (Ponssa \& Medina, 2016). This is consistent with the hypothesis that extrinsic pressures, such as head-first burrowing or ecological factors, have also played an important role in cranial evolution of the clade Adenomera + Leptodactylus. Compared to small-sized frogs, small-sized newts have different patterns of skull allometry (i.e., they show in general high shape/size change rates; Ivanović et al., 2007). The lack of a clear effect of adult absolute body size on skull allometry was also found in rodents (Giannini, 2014), suggesting that allometric divergence can be also highly adaptive.

Body size increases significantly in the basal clade of L. fuscus gr., which includes the largest species within the group, and at the base of the L. pentadactylus gr., which includes the largest species within the genus. Morphological features in adult skulls of large species (e.g., crista parotica extended, wide nasals and vomers, mandibular articulation posterior to condyle-occipital joint) are peramorphic traits regarding skull adult shapes of mid-sized species. According to our results, they are acquired through weak shape/size changes, along extended trajectories that start from already overdeveloped metamorphs. Likewise, in other large-sized anurans such as species of Horned frogs (Ceratophryidae), some peramorphic traits are early acquired during premetamorphic ontogeny (e.g., more caudal jaw articulation), constituting an example of larval heterochronies that influence the adult body plan (Fabrezi \& Quinzio, 2008). Although evolution of exceptionally large sizes occurred in several lineages of fossil and extant amphibians (among this latter, the Goliath frog, and cryptobranchid, amphiumid, and sirenid salamanders; Bonett, Chippindale, Moler, Van Devender, \& Wake, 2009; Sabater-Pi, 1985), gigantism is not well understood but apparently correlates with a slow developmental rate (Schoch, 2013). Data on age of large species of the L. pentadactylus gr. are lacking to explore whether their peramorphic shapes and rather low amounts of postmetamorphic shape/size change are related (as seen in other large anurans; Fabrezi \& Quinzio, 2008) to a postmetamorphic growth extended in time.

In summary, our data provide further evidence that the anuran skull is not a static structure during postmetamorphic stages and that the ontogenetic developmental patterns and the interspecific variation can be directly associated, with allometry having a fundamental impact on skull shape during the juvenile and adult stages in species of Leptodactylus. An analysis of the whole ontogenetic 
trajectory-including larval stages-would be insightful, thus allowing to discern the extent at which allometric patterns may pass through metamorphosis (e.g., the otic region becomes smaller with growth in both pre- and post-metamorphic stages; Larson, 2005), or whether the metamorphosis represents a reset point where new patterns may arise (Ivanović et al., 2011). Our study also emphasizes that wide-scale comparisons of growth patterns represent a potentially rich record of information in relation to understanding the plasticity of allometric patterns, evolutionary changes, and the polarity of such changes. Further studies on functional, biomechanical, and ecological factors will be needed to provide more information about the variables shaping anuran skulls during postmetamorphic growth.

\section{ACKNOWLEDGMENTS}

We are grateful to the herpetological collections of Instituto de Herpetología (Fundación Miguel Lillo; FML), Instituto de Biología Subtropical (Laboratorio de Genética Evolutiva, CONICET-UNaM; LGE), Museo de La Plata (UNLP), Universidade Estadual Paulista ( $\mathrm{CFBH})$, Museu de Zoologia Universidade de São Paulo (MZUSP), Museu Nacional de Rio de Janeiro (MNRJ), American Museum of Natural History (AMNH), University of Kansas Natural History Museum (KU), Museo de Zoología (Pontificia Universidad Católica del Ecuador; QCAZ), and Natural Museum of Natural History (Smithsonian Institution, USNM) for the loan of specimens employed in this study, and to Instituto de Herpetología (FML) for providing working space for our research. Three anonymous reviewers made valuable corrections that highly improved our manuscript. This study was funded by FONCYT (grant no. BID 2015 PICT 1618).

\section{ORCID}

Ana S. Duport-Bru (D) http://orcid.org/0000-0002-46197799

\section{REFERENCES}

Adams, D. C., \& Nistri, A. (2010). Ontogenetic convergence and evolution of foot morphology in European cave salamanders (Family: Plethodontidae). BMC Evolutionary Biology, 10, 216.

Adams, D. C., Collyer, M. L., \& Kaliontzopoulou, A. (2018). Geomorph: Software for geometric morphometric analyses. $\mathrm{R}$ package version 3.0.6. Retrieved from https://cran.r-project.org/package $=$ geomorph

AmphibiaWeb (2017). AmphibiaWeb. University of California, Berkeley, CA, USA. Retrieved from http://amphibiaweb.org

Birch, J. M. (1999). Skull alometry in the marine toad, Bufo marinus. Journal of Morphology, 241, 115-126.
Bonett, R. M., Chippindale, P. T., Moler, P. E., Van Devender, R. W., \& Wake, D. B. (2009). Evolution of gigantism in amphiumid salamanders. PLOS One, 4, e5615.

Cardini, A., Polly, D., Dawson, R., \& Milne, N. (2015). Why the long face? Kangaroos and wallabies follow the same 'rule' of cranial evolutionary allometry (CREA) as placentals. Evolutionary Biology, 42, 169-176.

Cock, A. G. (1966). Genetical aspects of metrical growth and form in animals. The Quarterly Review of Biology, 41, 131-190.

Collyer, M. L., \& Adams, D. C. (2013). Phenotypic trajectory analysis: Comparison of shape change patterns in evolution and ecology. Hystrix, 24, 75-83.

Cvijanović, M., Ivanović, A., Kalezić, M. L., \& Zelditch, M. L. (2014). The ontogenetic origins of skull shape disparity in the Triturus cristatus group. Evolution \& Development, 317, 306-317.

de Sá, R. O., Grant, T., Camargo, A., Heyer, W. R., Ponssa, M. L., \& Stanley, E. (2014). Systematics of the neotropical genus Leptodactylus Fitzinger, 1826 (Anura: Leptodactylidae): Phylogeny, the relevance of non-molecular evidence, and species accounts. South American Journal of Herpetology, 9, S1-S100.

Drake, A. G., \& Klingenberg, C. P. (2008). The pace of morphological change: Historical transformation of skull shape in St Bernard dogs. Proceedings of the Royal Society B: Biological Sciences, 275, 71-76.

Duellman, W. E., \& Trueb, L. (1986). Biology of amphibians. Baltimore, MD: The John Hopkins University Press.

Emerson, S. B. (1985). Skull shape in frogs: Correlations with diet. Herpetologica, 41, 177-188.

Emerson, S. B., \& Bramble, D. M. (1993). Scaling, allometry, and skull design. In Hanken, J., \& Hall, B. K. (Eds.), The skull functional and evolutionary mechanism (3, pp. 384-421). Chicago, IL: University of Chicago Press.

Esquerré, D., Sherratt, E., \& Keogh, J. S. (2017). Evolution of extreme ontogenetic allometric diversity and heterochrony in pythons, a clade of giant and dwarf snakes. Evolution, 71, 2829-2844.

Fabrezi, M. (2006). Morphological evolution of Ceratophryinae (Anura, Neobatrachia). Journal of Zoological Systematics and Evolutionary Research, 44, 153-166.

Fabrezi, M., \& Quinzio, S. I. (2008). Morphological evolution in Ceratophryinae frogs (Anura, Neobatrachia): The effects of heterochronic changes during larval development and metamorphosis. Zoological Journal of the Linnean Society, 154, 752-780.

Fabrezi, M., Quinzio, S. I., Goldberg, J., Cruz, J. C., Pereyra, M. C., \& Wassersug, R. J. (2016). Developmental changes and novelties in ceratophryid frogs. EvoDevo, 7, 1-16.

Felsenstein, J. (1985). Phylogenies and the comparative method. The American Naturalist, 125, 1-15.

Flores, D. A., Giannini, N., \& Abdala, F. (2018). Evolution of postweaning skull ontogeny in New World opossums (Didelphidae). Organisms Diversity \& Evolution, 18, 367-382.

Giannini, N. P. (2014). Quantitative developmental data in a phylogenetic framework. Journal of Experimental Zoology Part B: Molecular and Developmental Evolution, 322, 558-566.

Giannini, N. P., \& Goloboff, P. A. (2010). Delayed-response phylogenetic correlation: An optimization-based method to test covariation of continuous characters. Evolution, 64, 1885-1898. 
Goloboff, P. A., \& Catalano, S. A. (2016). TNT version 1.5, including a full implementation of phylogenetic morphometrics. Cladistics, 32, 221-238

Gonzalez, P. N., Perez, S. I., \& Bernal, V. (2011). Ontogenetic allometry and cranial shape diversification among human populations from South America. The Anatomical Record: Advances in Integrative Anatomy and Evolutionary Biology, 294, 1864-1874.

Gould, S. J. (1966). Allometry and size in ontogeny and phylogeny. Biological Reviews, 41, 587-638.

Gould, S. J. (1977). Ontogeny and phylogeny. Cambridge, MA: Harvard University Press.

Hanken, J., \& Hall, B. K. (1993). Mechanisms of skull diversity and evolution. In Hanken, J., \& Hall, B. K. (Eds.), The skull functional and evolutionary mechanism (3, pp. 1-36). Chicago, IL: University of Chicago Press.

Hipsley, C. A., \& Müller, J. (2017). Developmental dynamics of ecomorphological convergence in a transcontinental lizard radiation. Evolution, 71, 936-948.

Ivanović, A. N. A., \& Arntzen, J. W. (2014). Evolution of skull and body shape in Triturus newts reconstructed from threedimensional morphometric data and phylogeny. Biological Journal of the Linnean Society, 113, 243-255.

Ivanović, A. N. A., \& Arntzen, J. W. (2018). Evolution of skull shape in the family Salamandridae (Amphibia: Caudata). Journal of Anatomy, 232, 359-370.

Ivanović, A., Cvijanović, M., \& Kalezić, M. L. (2011). Ontogeny of body form and metamorphosis: Insights from the crested newts. Journal of Zoology, 283, 153-161.

Ivanović, A. N. A., Vukov, T. D., Džukić, G., Tomašević, N., \& Kalezić, M. L. (2007). Ontogeny of skull size and shape changes within a framework of biphasic lifestyle: A case study in six Triturus species (Amphibia, Salamandridae). Zoomorphology, 126, 173-183.

Klingenberg, C. P. (1998). Heterochrony and allometry: The analysis of evolutionary change in ontogeny. Biological Reviews, 73, 79-123.

Klingenberg, C. P. (2011). MORPHOJ: An integrated software package for geometric morphometrics. Molecular Ecology Resources, 11, 353-357.

Klingenberg, C. P. (2016). Size, shape, and form: Concepts of allometry in geometric morphometrics. Development Genes and Evolution, 226, 113-137.

Klingenberg, C. P., \& Gidaszewski, N. A. (2010). Testing and quantifying phylogenetic signals and homoplasy in morphometric data. Systematic Biology, 59, 245-261.

Klingenberg, C. P., \& Marugán-Lobón, J. (2013). Evolutionary covariation in geometric morphometric data: Analyzing integration, modularity, and allometry in a phylogenetic context. Systematic Biology, 62, 591-610.

Klingenberg, C. P., \& Zimmermann, M. (1992). Static, ontogenetic, and evolutionary allometry, a multivariate comparison in nine species of water striders. The American Naturalist, 140, 601-620.

Klingenberg, C. P., Debat, V., \& Roff, D. A. (2010). Quantitative genetics of shape in cricket wings: Developmental integration in a functional structure. Evolution: International Journal of Organic Evolution, 64, 2935-2951.

Larson, P. M. (2005). Ontogeny, phylogeny, and morphology in anuran larvae: Morphometric analysis of cranial development and evolution in Rana tadpoles (Anura: Ranidae). Journal of Morphology, 264, 34-52.

Mitteroecker, P., Gunz, P., Windhager, S., \& Schaefer, K. (2013). A brief review of shape, form, and allometry in geometric morphometrics, with applications to human facial morphology. Hystrix, The Italian Journal of Mammalogy, 24, 59-66.

Openshaw, G. H., \& Keogh, J. S. (2014). Head shape evolution in monitor lizards (Varanus): Interactions between extreme size disparity, phylogeny and ecology. Journal of Evolutionary Biology, 27, 363-373.

Pélabon, C., Bolstad, G. H., Egset, C. K., Cheverud, J. M., Pavlicev, M., \& Rosenqvist, G. (2013). On the relationship between ontogenetic and static allometry. The American Naturalist, 181, 195-212.

Piras, P., Salvi, D., Ferrara, G., Maiorino, L., Delfino, M., Pedde, L., \& Kotsakis, T. (2011). The role of post-natal ontogeny in the evolution of phenotypic diversity in Podarcis lizards. Journal of Evolutionary Biology, 24, 2705-2720.

Ponssa, M. L. (2008). Cladistic analysis and osteological descriptions of the frog species in the Leptodactylus fuscus species group (Anura, Leptodactylidae). Journal of Zoological Systematics and Evolutionary Research, 46, 249-266.

Ponssa, M. L., \& Heyer, W. R. (2007). Osteological characterization of four putative species of the genus Adenomera (Anura: Leptodactylidae), with comments on intra- and interspecific variation. Zootaxa, 54, 37-54.

Ponssa, M. L., \& Medina, R. G. (2016). Comparative morphometrics in leptodactylinae frogs (Anura, Leptodactylidae, Leptodactylinae): Does burrowing behavior relate to sexual dimorphism? Journal of Herpetology, 50, 604-615.

Ponssa, M. L., \& Vera Candioti, M. F. (2012). Patterns of skull development in anurans: Size and shape relationship during postmetamorphic cranial ontogeny in five species of the Leptodactylus fuscus group (Anura: Leptodactylidae). Zoomorphology, 131, 349-362.

Rohlf, F. J. (2013). TpsDig 2.17. Ecology \& Evolution, Stony Brook, NY: SUNY at Stony Brook.

Sabater-Pi, J. (1985). Contribution to the biology of the giant frog (Conraua goliath, Boulenger). Amphibia-Reptilia, 6, 143-153.

Schoch, R. R. (2013). How body size and development biased the direction of evolution in early amphibians. Historical Biology, 25, 155-165.

Segura, V., Cassini, G. H., \& Prevosti, F. J. (2016). Threedimensional cranial ontogeny in pantherines (Panthera leo, $P$. onca, P. pardus, P. tigris; Carnivora: Felidae). Biological Journal of the Linnean Society, 120, 210-227.

Shea, B. T. (1985). Ontogenetic allometry and scaling: A discussion based on the growth and form of the skull in African apes. In W. L. Jungers (Ed.), Size and scaling in primate biology (pp. 175-205). New York, NY: Plenum Press.

Sherratt, E., Gower, D. J., Klingenberg, C. P., \& Wilkinson, M. (2014). Evolution of cranial shape in caecilians (Amphibia: Gymnophiona). Evolutionary Biology, 41, 528-545.

Sherratt, E., Vidal-García, M., Anstis, M., \& Keogh, J. S. (2017). Adult frogs and tadpoles have different macroevolutionary patterns across the Australian continent. Nature Ecology \& Evolution, 1, 1385-1391.

Simon, M. N., \& Marroig, G. (2017). Evolution of a complex phenotype with biphasic ontogeny: Contribution of development versus 
function and climatic variation to skull modularity in toads. Ecology and Evolution, 7, 10752-10769.

Simon, M. N., Machado, F. A., \& Marroig, G. (2016). High evolutionary constraints limited adaptive responses to past climate changes in toad skulls. Proceedings of the Royal Society B: Biological Sciences, 283, 20161783.

Strelin, M. M., Benitez-Vieyra, S., Fornoni, J., Klingenberg, C. P., \& Cocucci, A. (2016). Exploring the ontogenetic scaling hypothesis during the diversification of pollination syndromes in Caiophora (Loasaceae, subfam. Loasoideae). Annals of Botany, 117, 937-947.

Strelin, M. M., Benitez-Vieyra, S., Fornoni, J., Klingenberg, C. P., \& Cocucci, A. (2018). The evolution of floral ontogenetic allometry in the Andean genus Caiophora (Loasaceae, subfam. Loasoideae). Evolution \& Development, 20, 29-39.

Tavares, W. C., Pessôa, L. M., \& Seuánez, H. N. (2016). Phylogenetic and size constrains on cranial ontogenetic allometry of spiny rats (Echimyidae, Rodentia). Journal of Evolutionary Biology, 29, 1752-1765.

Trueb, L., \& Alberch, P. (1985). Miniaturization and the anuran skull, a case study of heterochrony. Vertebrate Morphology, 30, 113-121.

Trueb, L., Púgener, L. A., \& Maglia, A. M. (2000). Ontogeny of the bizarre: An osteological description of Pipa pipa (Anura: Pipidae), with an account of skeletal development in the species. Journal of Morphology, 243, 75-104.

Urošević, A., Ljubisavljević, K., \& Ivanović, A. (2013). Patterns of cranial ontogeny in lacertid lizards: Morphological and allometric disparity. Journal of Evolutionary Biology, 26, 399-415.

Vera, M. C., \& Ponssa, M. L. (2014). Skeletogenesis in anurans: Cranial and postcranial development in metamorphic and postmetamorphic stages of Leptodactylus bufonius (Anura: Leptodactylidae). Acta Zoologica, 95, 44-62.

Vukov, T., Krstičić, J., Petrović, T., \& Tomašević Kolarov, N. (2018). Patterns of cranial sexual dimorphism in the yellow-bellied toad
(Bombina variegata, Bombinatoridae). North-Western Journal of Zoology, 14, 44-49.

Wassersug, R. J. (1976). A procedure for differential staining of cartilage and bone in whole formalin-fixed vertebrates. Stain Technology, 51, 131-134.

Weston, E. M. (2003). Evolution of ontogeny in the hippopotamus skull: Using allometry to dissect developmental change. Biological Journal of the Linnean Society, 80, 625-638.

Wilson, L. A. B. (2013). Allometric disparity in rodent evolution. Ecology and Evolution, 3, 971-984.

Wilson, L. A. B., \& Sánchez Villagra, M. R. (2011). Evolution and phylogenetic signal of growth trajectories: The case of chelid turtles. Journal of Experimental Zoology Part B: Molecular and Developmental Evolution, 316, 50-60.

Yeh, J. (2002a). The effect of miniaturized body size on skeletal morphology in frogs. Evolution; International Journal of Organic Evolution, 56, 628-641.

Yeh, J. (2002b). The evolution of development: Two portraits of skull ossification in pipoid frogs. Evolution, 56, 2484-2498.

\section{SUPPORTING INFORMATION}

Additional supporting information may be found online in the Supporting Information section.

How to cite this article: Duport-Bru AS, Ponssa ML, Vera Candioti F. Postmetamorphic ontogenetic allometry and the evolution of skull shape in Nest-building frogs Leptodactylus (Anura: Leptodactylidae). Evolution \& Development. 2019;21:265-277. https://doi.org/10.1111/ede.12303 